\title{
Peculiarities of the buffalo species for andrological evaluation - results of four years of study and weekly semen collection schedule
}

\author{
Marc Henry', Mayara Ferreira Brito, Beatriz Parzewski Neves, Patrícia Alencar Auler, Jaci Almeida, \\ Guilherme Oliveira Andrade, Verónica Becerra Becerra, Luisa Bergmann
}

Escola de Veterinária, Centro de Biotecnologia em Bubalinocultura (CBB), Universidade Federal de Minas Gerais (UFMG), Belo Horizonte, MG, Brasil.

\begin{abstract}
The aim of the present review is to provide complementary information about reproductive characteristics of male buffaloes having as perspective a four - year-study based on a weekly seminal collection schedule and collection of data in partner properties of several regions of Brazil. Aspects of testicular growth, reproductive behavior and characteristics of 1477 ejaculates of 13 donors are discussed in conjunction with data available in the literature.
\end{abstract}

Keywords: sperm quality, testicular growth, sexual behavior.

\section{Introduction}

An andrological evaluation should be part of the clinical exam of breeders, aiming at reducing the probability of failure in reproductive management. The absence or poor reproductive selection of males and females is one of the main causes of economic loss of contemporary productive systems. The early exclusion of animals with problems or low reproductive performance is one of the goals to be achieved through veterinary advice. Within this context, andrological examination can identify precocious animals (genetic selection guideline), sub or infertile animals or animals ready for reproduction. In addition, an andrological examination should be performed when one intends to advise on purchase or sale of bulls.

The aim of this review is to present and discuss data raised by the Center of Biotechnology in Buffaloes (CBB)-EV-UFMG, Pedro Leopoldo-MG, contextualizing them with those of the current literature. In this context, aspects of testicular growth, reproductive behavior and methods of semen collection in buffalo males will be addressed. Also, the results of seminal evaluation of bulls collected weekly during a period of four years will be presented.

\section{Scrotal circumference growth curves of buffaloes}

It is well established in several species that testicular development has a positive correlation with body development and that knowledge of scrotal circumference per age is a good tool to aid genetic selection programs and diagnose developmental abnormalities. Also, in crossbred buffaloes, Ohashi et al. (2001) found a highly positive correlation between age and body weight and scrotal circumference. Scrotal circumference is often used for male selection, since it is a parameter of easy measurement, has high repeatability and moderate to high heritability. In addition, scrotal circumference has a favorable correlation with qualitative and quantitative semen characteristics, age at puberty, sexual precocity and weight gain (Bergmann et al., 1997; Loaiza-Echeverri et al., 2013).

To interpret findings of scrotal circumference, the ideal would be to use reference tables of testicular size/age by breed, which are not always available. In addition, it is essential to remember that many factors influence testicular size, particularly during the growth phase. Among these factors, age/weight, nutrition, environmental temperature and type of management can be cited, added to the genetic and racial components of each herd. A concern of technicians regarding the use of scrotal circumference/age reference tables for the buffalo specie resides in the absence of tables by breed in addition to the reduced number of animals evaluated per age group. Also questioned is the acuity of values presented in such reference tables since they can be influenced by the nutritional management condition of the evaluated population.

It is known, for cattle, that a feed restriction during lactation or post weaning growing phase (Barth et al., 2008) can lead to a compromise of body and testicular development that cannot be compensated even in sexually mature animals. In dairy buffaloes, calves during lactation may be more easily exposed to inadequate nutritional management due to the wish to maximize milk production. The construction of reference tables including animals subjected to poor nutritional management may not express the true values of the genetic potential of these populations. Therefore, it is fundamental that the technician using reference tables as a guide does so considering these aspects, incorporating in their interpretation the variables that may have influenced their scrotal perimeter findings. Considering the impact of this measure can have on a genetic selection program, it is essential to be continuously attentive to management factors, minimizing their effects on the testicular development of the herds. Reference data are useful to know in which situation the animals under evaluation are, and it is highly recommended that these tables are continuously updated, incorporating the genetic advance of the breeds. The general rule to be followed for selecting a breeder is to search for animals with a larger scrotal circumference (in the absence of any pathology) per age group. It is worth mentioning that the intensity of 
selection applied will depend on the objective and the situation in which the herd in evaluation is. The comparison between contemporaries raised under the same management, is a good start.

Table 1 shows an overview of the expression of testicular growth in buffaloes from the compilation of 2,595 data, obtained from 1,964 animals including several breeds (Murrah, Mediterranean, Jafarabadi and crosses) from 16 farms, raised extensively, in three geographically distinct regions of the Brazilian territory (A - North, B - Northeast and C - Southeast). Measurements and weight of animals from both beef and dairy farms were included in the study.

The average scrotal circumference per age group in this study was lower compared to the studies of Ohashi (1993) and Vale et al. (2004), cited by Colégio Brasileiro de Reprodução Animal- CBRA (2013), each study based on restricted number of animals and selected herds. A relevant point among the studies refers to the number of animals evaluated, which reduced or increased the diversity of the assessed population, either considering the genetic ground or the diversity of management factors incorporated in each group. Regardless of the origin of the differences on testicular circumferences by age seen among studies, it can be inferred that the average scrotal circumference obtained per each age group in the two studies with higher values (Ohashi, 1993; Vale et al. (2004), cited by CBRA (2013) is the most desirable for bubaline specie, at least, until new studies indicate another tendency. The present study better represents the current situation of the population. Considering the maximum values of scrotal circumference obtained (Table 1), it can be noted, even in this more heterogeneous population, that in the per age category some males showed similar scrotal circumferences than the ones found in the two studies with higher values. Attention should be drawn to the great variability of scrotal circumference by age found in this heterogeneous population. Among the different causes that could explain this finding, the genetic base cannot be excluded. The great variability in scrotal circumference per age category is a stimulus to build consistent selection programs which will include scrotal circumference as one of the parameters to be evaluated. Therefore, the technician when advising adjustments in general buffalo management has in those scrotal circumference studies a reference support to decide which bull (s) should be kept on a farm. It is expected that the cutting line to maintain or discard a bull would be different among properties in a given moment; however, the goal to be achieved over time should be similar.

Table 1. Scrotal circumference and body weight of buffalo bulls (Bubalus bubalis) raised under extensive management in three regions of Brazil

\begin{tabular}{|c|c|c|c|c|c|c|c|c|}
\hline \multirow{2}{*}{$\begin{array}{c}\text { Age } \\
\text { (months) }\end{array}$} & \multicolumn{4}{|c|}{ Scrotal circumference $(\mathrm{cm})$} & \multicolumn{4}{|c|}{ Body Weight (Kg) } \\
\hline & $\mathrm{n}^{* *}$ & Average & Minimum & Maximum & $\mathrm{n}^{* *}$ & Average & Minimum & Maximum \\
\hline $3-12$ & 258 & 14,0 & 7,5 & 24 & 219 & 154,8 & 71 & 387 \\
\hline$>12-\leq 18$ & 764 & 17,3 & 9 & 31,5 & 574 & 215,3 & 88 & 673 \\
\hline$>18-\leq 24$ & 531 & 20,3 & 12 & 30 & 456 & 293,2 & 137,5 & 540 \\
\hline$>24-\leq 30$ & 425 & 22,9 & 8 & 33 & 371 & 353,8 & 155 & 582 \\
\hline$>30-\leq 36$ & 267 & 25,0 & 11,5 & 34 & 259 & 420,7 & 139,5 & 846 \\
\hline$>36-\leq 42$ & 174 & 26,6 & 17 & 36 & 166 & 451,7 & 240 & 692 \\
\hline$>42-\leq 48$ & 52 & 28,0 & 20,5 & 33 & 45 & 517,5 & 290 & 876 \\
\hline$>48-\leq 54$ & 56 & 27,9 & 21,5 & 34 & 50 & 515,7 & 300 & 790 \\
\hline$>54-\leq 60$ & 16 & 29,4 & 24,5 & 34 & 8 & 483,4 & 305 & 674 \\
\hline$>60-\leq 66$ & 12 & 31,4 & 28 & 36 & 11 & 620,8 & 450 & 790 \\
\hline$>66-\leq 72$ & 5 & 31,1 & 26,5 & 37 & 4 & 565,3 & 464 & 682 \\
\hline$>72$ & 35 & 32,6 & 26 & 39 & 29 & 701,6 & 550 & 970 \\
\hline
\end{tabular}

*1.964 bulls were evaluated (single measurement or repeated in subsequent evaluation periods); $\mathrm{n}^{* *}=$ data number obtained by age group.

In the large evaluated population, when data were analyzed by region, there were some differences in scrotal circumference growth pattern between regions (Figure 1). It is worth to highlight that regions " $\mathrm{B}$ " and "C" concentrated a higher number of dairy farms where the calves were fed through partial nursing or with maternal milk substitutes. In contrast, in region " $\mathrm{A}$ ", most of the farms were beef farms, where calves were kept suckling for a longer period. It can be noticed that in region " $A$ ", in the initial phase of the animal's development (lower ages), testicular size by age was higher than in the other two regions (" $\mathrm{B}$ " and " $\mathrm{C}$ "). The different types of farm (beef $\mathrm{X}$ dairy) and climate differences between regions, which could alter the annual availability of food, support the possibility that better nutrition could be associated with the largest scrotal circumference found in the initial phase of testicular development in region " $\mathrm{A}$ " animals (the region with the highest annual rainfall index). It is interesting to note that this difference disappears in older animals.

Some nonlinear regression models have been used to help to estimate testicular development at different ages and may be useful for early selection of breeding stock. (Loiaza-Echeverri et al., 2013). Through this model, it was possible to notice that the scrotal 
circumferences at the inflection point of the curves were similar $(16 \mathrm{~cm}, 17 \mathrm{~cm}$ and $15 \mathrm{~cm})$ for Jafarabadi, Mediterranean and Murrah breed. But age at the occurrence of the inflection point varied among breeds (396, 201 and 215 days, respectively, for Jafarabadi, Mediterranean and Murrah breed) (Henry et al., 2013). The inflection point represents the testicular circumference when maximum testicular parenchyma proliferation occurred (highest testicular growth rate) and may be related to puberty (Quirino et al., 1999; Silva et al., 2002 - bovines). Based on this assumption, Jafarabadi breed appears to have a later sexual development when compared to the other two breeds evaluated (Henry et al., 2013).

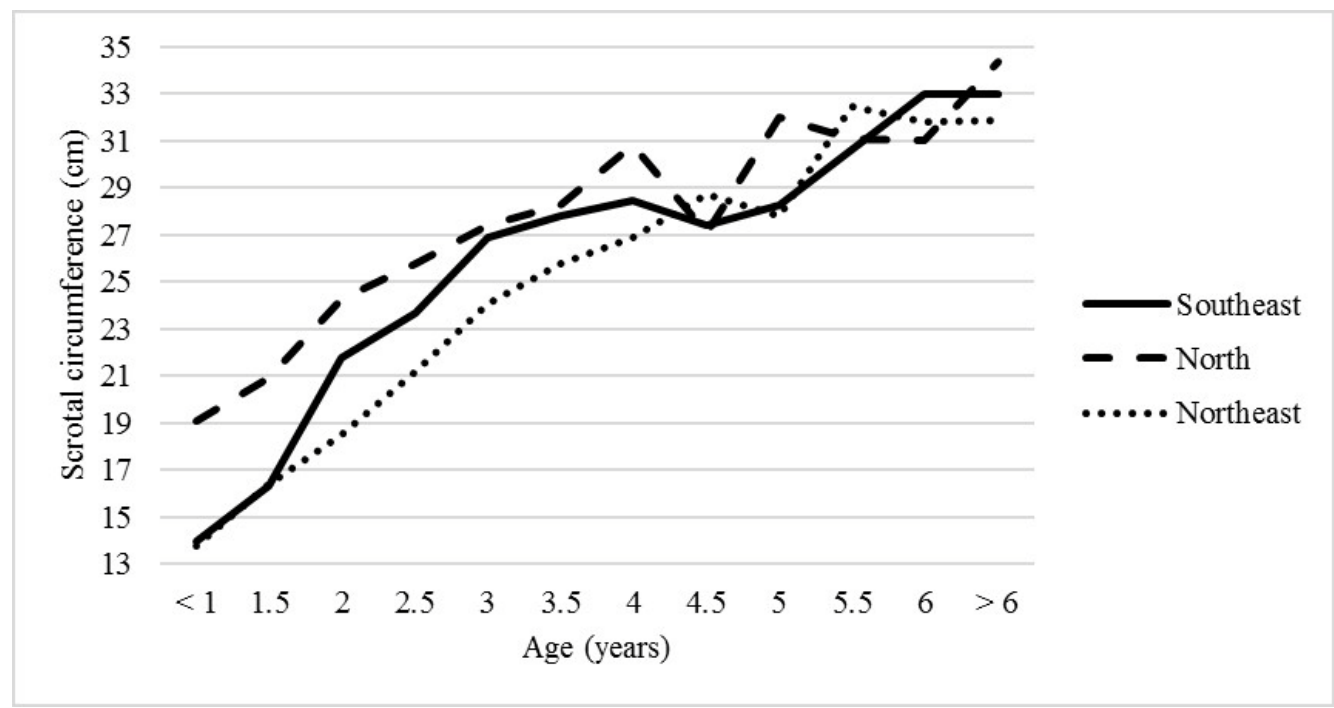

Figure 1. Scrotal circumference growth curve of buffaloes raised under extensive management in three regions of Brazil (A-North, B-Northeast and C-Southeast)

\section{Sexual behavior of male buffaloes and seminal collection}

The sexual behavior of a bull includes two components: sexual desire or libido and mating ability (Chenoweth, 1983). Libido is defined as the willingness and eagerness to mount and to complete copulation (Hultnas, 1959) and mating ability can be characterized analyzing the posture of the male during mount, ejaculation and dismount (Chenoweth, 1981; Anzar et al., 1993).

During a one -year- period of weekly seminal collection attempts of 13 buffaloes, behaviour expressions during courtship were recorded. Most of the behaviors shown were similar to those reported as part of the sexual courtship of several species. According to the decreasing frequency of occurrence, behaviors expressed by bulls presented to a restrained dummy female from the beginning of the interaction up to seminal collection were: smelling the vulva, Flehmen reflex, incomplete mating (animal exposes the penis, but does not ejaculate), licking the vulva, mounting without penile exposure, intermittent exposure of penis prior to mount, chin rump resting and head beat on female body parts. These behaviors were also reported in studies by Anzar et al. (1993) and Samo et al. (2005). Johari (1960) draws the attention to the occurrence of Flehmen reflex and repetitive small penile movements with a projection of the penis by a few centimeters out of the preputial ostium.

The contracture of the preputial sheath during the interaction of the male with the female was indicative of ongoing sexual excitation for all animals used in the CBB four-year-study. The expression of this behavior resulted, most of the time, in the mount and a successful attempt at seminal collection. The lack of manifestation of this signal was associated with momentary disinterest of the male, frequently leading to failure of the seminal collection attempt.

The time elapsed between detecting the first appropriate stimulus, such a female exhibiting estrus, until the complete mount is called reaction time (Chenoweth, 1997). In the bubaline specie, the reaction time may vary from 1 to 15 minutes, and appears not to be influenced by season (Dixit et al., 1984; Singh et al., 2001; Mandal et al., 2000; Samo et al., 2005; QuezadaCasasola et al., 2016). For the CBB animals on a oneyear-period record, the mean reaction time was $1.9 \pm 1.2$ minutes.

In this species, the act of copulation is fast, lasting only a few seconds, and the ejaculatory impulse is less marked than in cattle. After ejaculation, the buffalo slowly dismounts, and the penis is gradually retracted into the preputial sheath (Jainudeen and Hafez, 1995).

In the CBB group of bulls the success rate of weekly seminal collection attempt was over 90\% (476 trials) during a one- year- period. This success rate remained similar during the other three years. In this study, the maximum time allowed for male and female interaction was $10 \mathrm{~min}$. It has been observed that some individuals ejaculated at most attempts, while failure was most frequently associated to a restricted number of animals. The failures were most of the time punctual and transient. The main causes speculated as cause of loss of interest to ejaculate were: the occurrence of 
fights between males in the night before collection, high ambient temperature at collection, presence of strangers in the collection area, rejection of the female used as dummy, presence of a dominant bull in the surroundings of the collection area, among others. Using corrective measures for each suspicion was not fully successful. After a while, in subsequent collection attempts, some of these bulls showed again transient disinterest. It is believed that these failures are the result of an association of factors of difficult perception and control. Some males in comparison to others are more susceptible to temporary disinterest (intrinsic characteristic of the animal). In a study conducted in India, an unsuccessful rate of seminal collection attempts of thirty-four percent was reported without any apparent cause (Dixit et al., 1984). It was observed during the four- year- study that when the female dummy was in estrus, the interest of most males was expressed more vigorously and, in those occasions, the time required to mount and ejaculate and punctual failures were reduced. On the other hand, it is important to consider the report by Vale et al. (2008) that when heat is intense, the disinterest of buffaloes to ejaculate in an artificial vagina is more frequent even when facing a dummy female in estrus.

It has been reported that donor bulls at Semen Freezing Centers conditioned to ejaculate in the artificial vagina, became resistant to artificial service over time without any specific reason (Prabhu and Bhattacharya, 1954; Prabhu, 1956; Silva A.O.A., personal communication, 2012), making their stay in Semen Freezing Centers unsustainable. This one, among other problems, which has hampered a greater dissemination of the use of artificial insemination in this species.

The considerable success obtained in attempts to collect 13 bulls evaluated in the CBB could be related to the fact that they had been conditioned to artificial vagina seminal collection when they were young, in the peri-pubertal period, and that 12 out of 13 had never had the opportunity to mate a female, thus they were inexperienced bulls. The only male of this group who had previous field mating experience was one of the males who failed to ejaculate in the artificial vagina at several attempts.

Nine adult bulls from private properties that had previous field mating experience were submitted to seminal collection attempts using artificial vagina. In eight animals, this procedure was repeated for two or up to four consecutive years. In total, there were 26 periods of seminal collection attempts using as dummy a buffalo in estrus. In four periods (15\%) the success was not reached after 10 consecutive attempts. In those responding to the process it took one to six consecutive attempts to obtain an ejaculate. Three of the four unsuccessful attempt periods were with bulls that in the previous year(s) had accepted to ejaculate in the artificial vagina. Additionally, after achieving the first seminal collection, continuing attempts at regular intervals resulted in variable success among bulls

According to Sansone (2000), buffaloes are easily conditioned to ejaculate in an artificial vagina. From the standpoint of obtaining a semen sample which best represents the potentiality of production and seminal excretion of each animal there is no doubt that the artificial vagina is the best method to be used. The limitation of its use is to maintain the success of certain seminal donors to ejaculate continuously in prolonged seminal collection programs. That is one aspect that should be better studied to overcome failures. It is open for speculation whether buffaloes are more sensitive to this type of procedure or if a specific procedure needs to be identified and corrected to increase the success rate.

The methods of electroejaculation and massage of the vas deferens ampoules are alternative methods that could be used for the seminal collection. However, Ohashi (2008) advised against the use of electroejaculator considering that buffaloes are very sensitive to electrical stimulus. Some success was reported particularly in younger animals, however, in adult animals the risk of accident was considered too high (Ohashi et al., 2011). During the four-year- study period some success was obtained using electro-ejaculator in adult bulls. However, it is necessary to emphasize that in addition to the necessity of having a suitable structure for animal contention, the electrical stimulus needs to be increased in a very gradual manner avoiding high discharge. Anyway, in well-succeeded attempts seminal samples were incipient.

The massage of the vas deferens ampoules is another alternative; however, when a seminal sample is obtained it is generally of lower quality than that obtained with the artificial vagina or electroejaculation (Ohashi et al., 2011). Generally, the volume is sharply reduced, and due to the low participation of the cauda of the epididymis in the process, the sperm sample mainly derives from the upper part of the genital tract which may result in low sperm motility. Therefore, one should interpret the findings with caution, and in this situation, the spermatic morphology associated with a normal and proper development of the reproductive system, become parameters of great relevance to guide the evaluation.

For those cases when bull donors did not longer accept to ejaculate in a conventional artificial vagina, the use of an intravaginal device for semen collection, initially developed for bovine by Barth et al. (2004) was refined and adjusted for buffaloes. The device is anatomically adapted to be placed in a buffalo vagina, not being noticeable externally. The tests carried out demonstrated that it was an efficient method for seminal collection. Qualitatively, seminal samples obtained with the device were very similar to the ones collected by a conventional artificial vagina. The device was subjected to a patenting process (Application number BR 1020150324995).

\section{Characteristics of buffalo ejaculate collected by artificial vagina}

The weekly regimen of seminal evaluation of 13 buffaloes for four consecutive years resulted in the observation of significant changes in some seminal parameters from one collection to another. To better exemplify these findings, results are presented in Figure 3 by bull, collection attempt and by donor age. 
Fluctuations are easily noticeable in all seminal parameters and were more evident in some than in others. Therefore, results were summarized using various description forms presented in Table 2 and Figure 2. The objective is to allow the technician to better position himself against a finding in his day to day work.

The color of the buffalo's ejaculate may vary from white to yellowish, and the aspect from aqueous to creamy appearance, depending on the sperm concentration. The milky appearance (intermediate) predominated (Table 2). According to some authors, ejaculates with a higher sperm concentration may also have, when seen against the light, dark blue color streaks (Vale, 1994; Vale, 1997; Vale 2011).
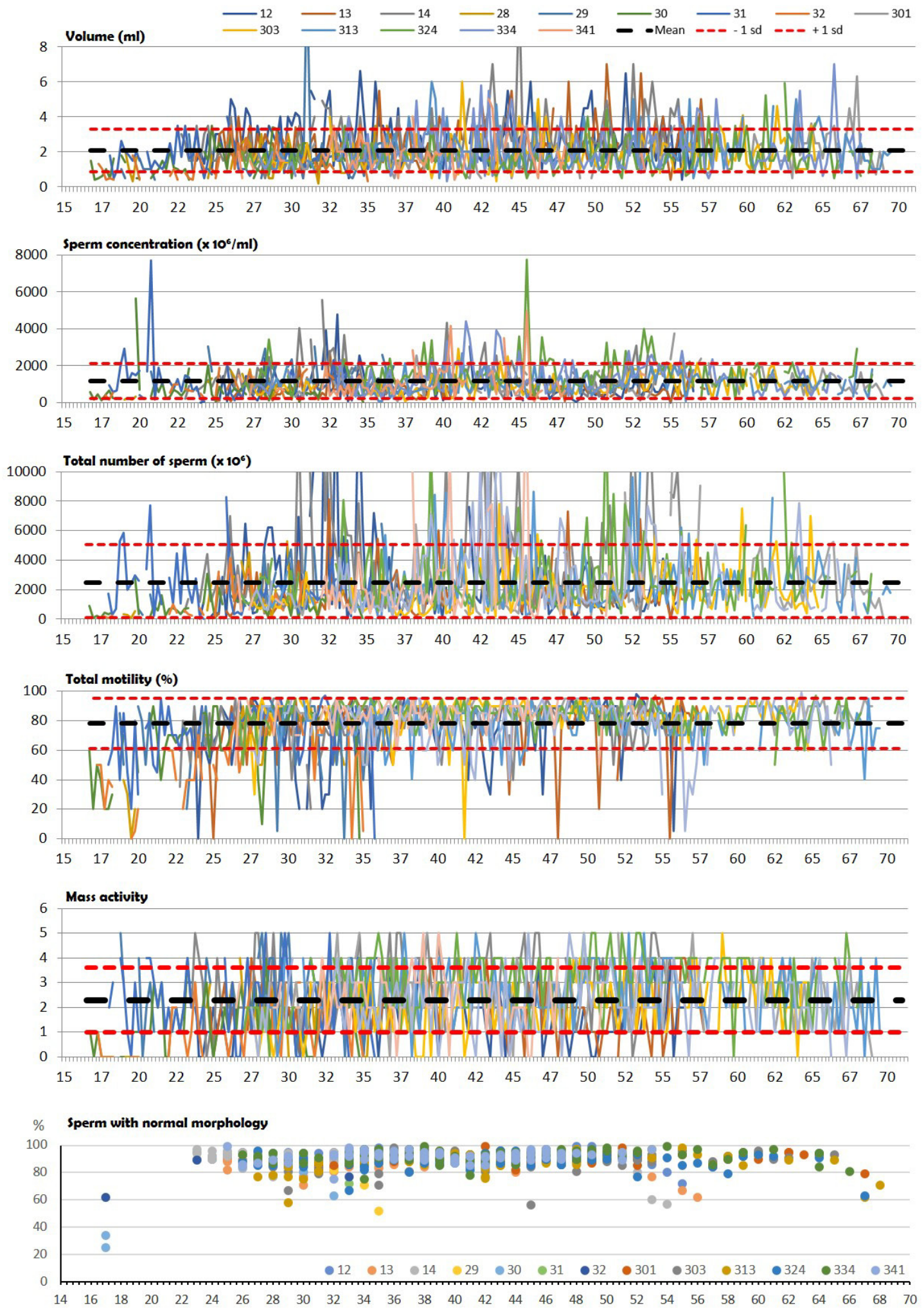

Figure 2 . Seminal characteristics of 13 buffaloes collected weekly by artificial vagina by bull and age (months). dotted black line $=$ general average; dotted red $=$ plus and minus standard deviations . 
Henry et al. Buffalo andrological evaluation.

Table 2. Seminal characteristics of 13 buffalo bulls submitted to a four- year- period of weekly seminal collection by artificial vagina

\begin{tabular}{lcccc}
\hline Semen characteristics & $\mathrm{n}^{*}$ & Mean $\pm \mathrm{sd}$ & Min - max & Frequent values \\
\hline Visual appearance & 1453 & aqueous - creamy & - & Milky \\
Volume (ml) & 1467 & $2,1 \pm 1,2$ & $0,2-11,0$ & $1,1-2,0$ \\
Mass activity $(0-5)$ & 1459 & $2,3 \pm 1,3$ & $0-5$ & 2 \\
Sperm motility $(\%)$ & 1463 & $78,0 \pm 17,0$ & $0-95$ & $\geq 80$ \\
Vitality $(1-5)$ & 1452 & $3,4 \pm 0,9$ & $1-5$ & 3 \\
Sperm concentration $\left(\mathrm{x} 10^{6} / \mathrm{ml}\right)$ & 1370 & $1.118,9 \pm 767,2$ & $17,5-7.760,0$ & $>500 \mathrm{a} \leq 1000$ \\
Total number of sperm $\left(\mathrm{x} 10^{6}\right) /$ ejaculate & 1361 & $2.429,7 \pm 2.418,5$ & $14,0-27.195,0$ & $>1000 \mathrm{a} \leq 2000$ \\
Sperm with normal morphology $(\%)$ & 760 & $89 \pm 9$ & $23-99$ & $\geq 90$ \\
\hline
\end{tabular}

${ }^{*} \mathrm{n}=$ number of samples assessed.

Seminal volume was a highly variable characteristic among buffaloes and ejaculates of a given donor. This parameter varied between 0.2 and $11 \mathrm{ml}$ (Table 2), values between 1.1 and $2.0 \mathrm{ml}$ were more frequent, corresponding to $43 \%$ of the ejaculates. Higher volumes were observed in older animals. Volumes ranging from 2.0 to $8.0 \mathrm{ml}$ have been reported (Javed et al., 2000; Pant et al., 2003; Vale, 2011; Zorzetto et al., 2016). According to Vale (2011), variation in seminal volumes can be observed in both young and adult bulls. While in sexually mature buffaloes the volume can vary from 4.0 to $8.0 \mathrm{ml}$, in young bulls, early in reproductive life, the ejaculates can vary between 1.0 to $3.0 \mathrm{ml}$.

An important quality parameter of an ejaculate is sperm motility and should be evaluated immediately after collection, subjectively, or by computerized methodology (CASA). The sperm motility of fresh semen ranges from 0 to $95 \%$, and high values $(\geq 80 \%)$ were more frequently found in the 13 bull groups (Table 2). According to Vale (2011), an ejaculate can be considered of excellent motility when it presents above $80 \%$ of motile spermatozoa and poor motility when it presents below $40 \%$.

Motility associated with concentration and sperm strength for dislocation directly influences another feature of the ejaculate, i.e., mass activity. In the group of animals evaluated for four years, when ejaculates presented $\geq 80 \%$ sperm motility and concentration ranged between 500 and $1000 \times 10^{6}$ spermatozoa $/ \mathrm{ml}$, the mass activity most frequently found was classified as"3", based on a scale of 0 to 5 (Table 2).

As for sperm concentration/production, a seminal characteristic that varies until the end of testicular growth when males reach full sexual maturity, it is expected that the sperm concentration varies between $500 \times 10^{6}$ to $1,200 \times 10^{6}$ spermatozoa per $\mathrm{ml}$ (Javed et al., 2000; Pant et al., 2003; Vale et al., 2008; Vale, 2011). In the long-term study, adult bulls showed a large variation in sperm concentration ranging from 17.5 to $7,760 \times 10^{6}$ spermatozoa per ml. Values between 500 and $1,000 \times 10^{6}$ were more frequent (Table 2; Figures 2 and 3 ) and were like the range of values mentioned above. A high fluctuation in volume and concentration values resulted, consequently, in a high variation in total number of sperm per ejaculate (from 14 to $27,195 \times 10^{6}$ ) (Table 2; Figure 2). To better position the technician dealing with reproduction in buffaloes, the incidence of values per category for volume, concentration and total number of sperm per ejaculate are presented in Figure 3.
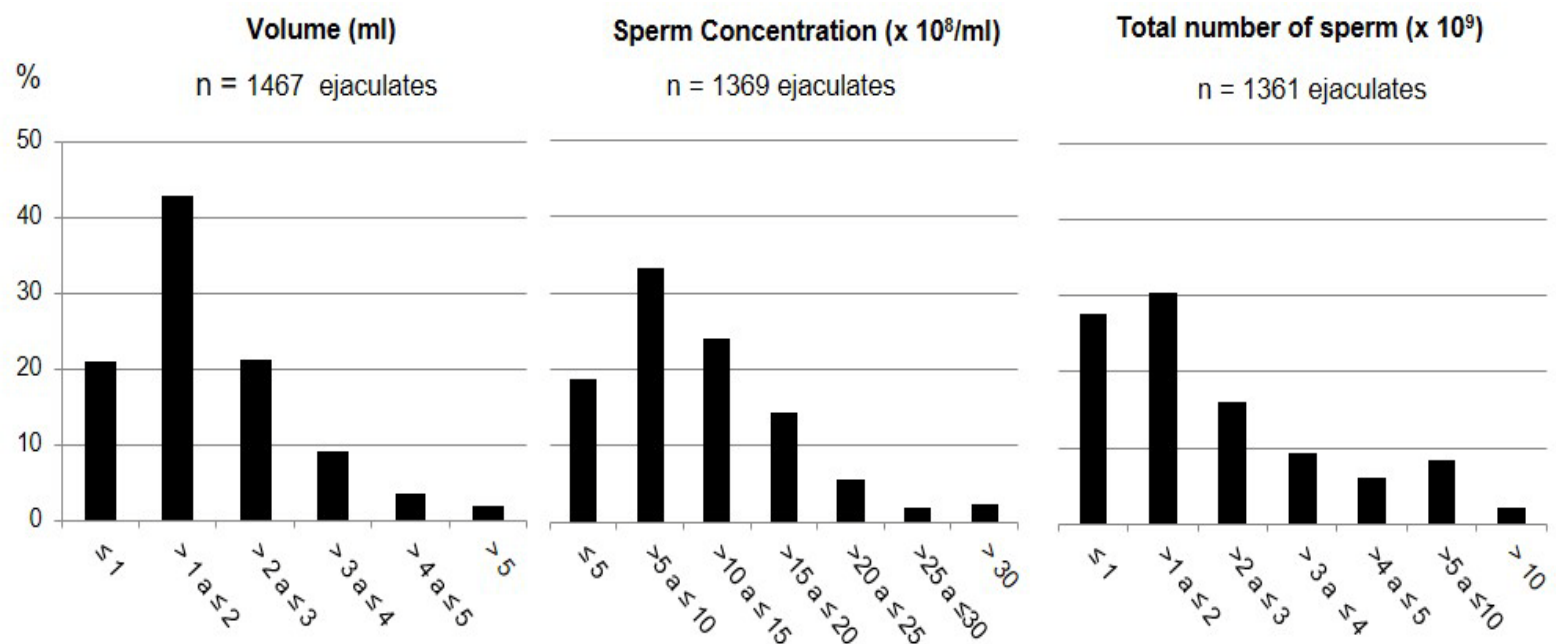

Figure 3. Proportion of ejaculates within each category of volume $(\mathrm{ml})$, sperm concentration $\left(\mathrm{x} 10^{6} / \mathrm{ml}\right)$ and total number of sperm $\left(\mathrm{x}^{9} 0^{9}\right)$ per ejaculate, in seminal samples collected weekly by artificial vagina for four consecutive years (13 buffaloes). 
The total percentage of sperm abnormalities for normal adult buffaloes, as well as other ruminants, should be at most 30.0\% (Vale, 1994; Vale, 1997; Vale, 2008). In buffalo species, sperm morphology defects have been associated with high inbreeding of the herds (Vale et al., 2008). However, as in other species, age has a significant effect on the incidence of sperm abnormalities (Saeed et al., 1990; Zorzetto et al., 2016), particularly in the near post-pubertal phase. Along the whole evaluation period, bulls under weekly seminal collection regimen presented most of the time a high percentage of morphologically normal spermatozoa $(\geq 80 \%)$ (Table 2 , Figure 2$)$ and no welldefined phase of testicular degeneration was detected.

It can be observed in Figure 3 that from 22 months of age onwards there was, aside from punctual larger fluctuations, a predominance of values fluctuating more frequently around a narrower range, which remained stable all over the evaluation period. In the period below 22 months of age, particularly 17 to 20 months, values for sperm morphology were under the required range. The undesirable values at this age period were associated to the near post-pubertal period of some donors which reflected a spermatogenesis and sperm maturation undergoing stabilization.

The large fluctuations in seminal parameter values detected throughout the evaluation period deserve attention. Considering the physiology of spermatogenesis and ejaculation, a finding of that extend would not be expected under normal circumstances. It is well established that under conditions of abnormality, for example, when a testicular degeneration or a disturbance of sperm maturation is in course seminal characteristics decay in quality, which may last for a variable time depending on the intensity and duration of the process. Most of the time, when substantial variations in some seminal parameters were detected, a regularization of these values occurred in subsequent seminal collection attempts (one-week interval), mischaracterizing a pathological process whose recovery would be gradual and for a variable, but prolonged period.

The question arises of what would be the cause (s) that lead to such fluctuations. Many could be depicted; however, it is worth to mention some. It should be remembered that for the process of artificial seminal collection, the technician submits the donor to a situation that diverges from the conditions found in the field (nature), the mannequin females are not necessarily in estrus and the collection process occurs in an atypical environment. Also, it is not uncommon to use over time one or very few females as mannequin. Another condition faced by bulls submitted to seminal collection by artificial vagina is the brief period (minutes) given for interaction with the female. During the long period of seminal collection attempts, differences among males as to the intensity of interest for the mannequin female, as well as differences as to the interest of a male to proceed to mount and ejaculation in the artificial vagina between different attempts were clearly evident. On several occasions, it was noticed that a male mounted and executed the galleys more due to conditioning than to a real interest and desire in copulating. It is important to stress that, in the presence of a female in estrus, the increase in interest of the males for the female was easily noticeable. That was even sticking when they were still in the waiting corral.

On the other hand, it is important to highlight that the interval between collections (one week) allowed sperm to accumulate in the cauda of the epididymis whose size varies from one donor to the other. This could account for part of the variations found, more specifically, the concentration and the total number of sperm per ejaculate. All those factors, individually or in combination, have the potential to influence the quality of the ejaculate different of what would be expected if the male passed through adequate sexual stimulation and reached full orgasm. Sperm number of an ejaculate depends on the full contractility of the spermatic reservoirs muscles as well as on the vas deferens and complementary structures. Thus, according to the degree of participation in the ejaculatory process of each of those structures, it can lead to a less concentrated sample and a predominantly older sperm population influencing seminal characteristics such as mass activity, sperm motile, strength of sperm cells displacement and total number of sperm per ejaculate.

The expression of homosexual behavior (male simulating copulation with another male) as described by Phillips (2002) was also observed in this group of buffalos. Observations were mainly made while donors were in the waiting corral. As there was no close control of their behavior while waiting, it can be hypothesized that in some occasions this would provide ground to a change in the seminal characteristics of a sample collected thereafter. In contrast, a semen donor that got extensively excited during the waiting period may have provided an atypical ejaculate thereafter. High volume, concentration or total number of spermatozoa per ejaculate could be expected.

The conditioning of animals to the process of seminal collection by artificial vagina is possible in many species. However, the maintenance of the success of a frequent and prolonged period of seminal collection regimen can vary among individuals and among species. Is the buffalo species more sensitive to human manipulation? The results point to this.

\section{Final considerations}

Here is the alert to technicians who work or intend to work with buffaloes to take extra care with this species, without excluding others, for the need to adequately weigh each finding of the andrological evaluation.

It is important to emphasize that scrotal circumference reference values herein presented, in addition to those available in the literature, are only a guide which allow positioning a given bull in comparison to others.

The importance of the results of sperm morphology associated to an adequate development of the genital system can be, in certain occasions, 
parameters of the greatest importance, considering that, at times values o f seminal parameters may fluctuate sharply between ejaculates without being associated to a specific cause.

The breeding soundness evaluation should embody all the characteristics of the genital system, the seminal quality in its various aspects, the libido and the copulation capacity of the male. In function of the degree of selection of each herd, the cut-out line may not be the same among herds, however, the goals to be achieved over time need to be similar.

It is true that the buffalo species deserves special attention. There is a long way to be achieved for the genetic selection of buffalo bulls. Good models used for other domestic species are known. The goal should always be to improve the reproductive capabilities of males and eliminate hereditary defects of the genital system.

\section{Acknowledgements}

To Fapemig and $\mathrm{CNPq}$ for the financial support. A production of the "INCT da Pecuária".

\section{References}

Anzar M, Ahmad M, Nazir M, Ahmad N, Shah IH. 1993. Selection of buffalo bulls: sexual behavior and its relationship to semen production and fertility. Theriogenology, 40:1187-1198.

Barth AD, Artega AA, Brito LFC, Palmer CW. 2004. Use of internal artificial vaginas for breeding soundness evaluation in range bulls: an alternative for electroejaculation allowing observations of sex drive and mating ability. Anim Reprod Sci, 84:315-325.

Barth AD, Brito LF, Kastelic JP. 2008. The effect of nutrition on sexual development of bulls. Theriogenology, 70:485-94.

Bergmann JAG, Quirino CR, Vale Filho VR, Fonseca CG. 1997. Herdabilidades e correlações genéticas entre medições testiculares e características espermáticas em touros nelore [in portuguese]. Arch Latinoam Prod Anim, 5:473-475.

Colégio Brasileiro de Reprodução Animal (CBRA) 2013. Manual para Exame Andrológico e Avaliação de Sêmen Animal [in portuguese]. 3 ed, Belo Horizonte: CBRA, 104p.

Chenoweth PJ. 1981. Libido and mating behavior in bulls, boars and rams. A review. Theriogenology, 16(2):155-177.

Chenoweth PJ. 1983. Sexual behavior of the bull: a review. J Dairy Sci, 66:173-179.

Chenoweth PJ. 1997. Bull libido/serving capacity. Vet Clin N Am -Food A, 13(2):331-342

Dixit NK, Agarwal SP, Dwaraknath PK. 1984. Seasonal variations in serum levels of thryroid hormones and their relation with seminal quality and libido in buffalo bulls. Theriogenology, 22(5):497-507.

Henry M, Brito MF, Loaiza-Echeverri AM, Oliveira CHS, Gibson AFB, Neves BP, Andrade GO, Melo IO, Bastianetto E. 2013. Scrotal Circunference growth curves of buffalo bulls of different breeds raised in
Brasil. Buff Bull, 32(2):439-442.

Hultnas CA. 1959. Studies on variation in mating behavior and semen picture in young bulls of the Swedish Red-and-White breed and on causes of this variations. Acta Agric Scand, 9(suppl. 6):1-82.

Jainudeen MR, Hafez ESE. 1995. Cattle and buffalo. In: Hafez ESE, Hafez, B. Reproduction in Farm Animals, 6th. Ed. Filadelfia: Lea and Febiger, p.315-329.

Javed MT, Khan A, Kausar R. 2000. Effect of age and season on some semen parameters of Nili-Ravi buffalo (Bubalus bubalis) bulls. Veterinarski Arhiv, 70(2):83-94.

Johari MP. 1960. Studies on the sexual physiology of water buffaloes. Indian Vet J, 37:354-364.

Loaiza-Echeverri AM, Bergmann JA, Toral FL, Osorio JP, Carmo AS, Mendonça LF, Moustacas VS, Henry M. 2013. Use of nonlinear models for describing scrotal circumference growth in Guzerat bulls raised under grazing conditions. Theriogenology, 79:751-759.

Mandal DK, Nagapaul PK, Gupta AK. 2000. Seasonal variation in seminal attributes and sexual behavior of Murrah buffalo bulls. Indian J Dairy Sci, 53(4)278-283.

Ohashi OM. 1993. Estudo morfofisiologico do testículo de búfalos mestiços (B. bubalis) em diferentes idades (Doutorado em Reprodução Animal) [in portuguese].Universidade Estadual Paulista, Botucatu, São Paulo, Brazil. 111p.

Ohashi OM, Oba E, Nogueira JC, Sousa JS, Silva AOA. 2001. Characteristics of the reproductive development of male buffalo: testicular development, puberty and sexual maturity [in portuguese]. Rev Bras Reprod Anim, (23)103-107.

Ohashi OM. 2008. Inseminação artificial em bubalinos. In: Gonçalves PBD. Biotécnicas aplicadas à reprodução animal [in portuguese]. 2.ed. Roca, p.97-110.

Ohashi OM, Santos SSD, Miranda MS, Cordeiro MS, Costa NN, Silva TVG. 2011. Morfologia do sistema genital, distúrbio reprodutivo e manejo do macho bubalino (Bubalus bubalis) [in portuguese]. Rev Bras Reprod Anim, 35(2):p.88-94

Pant HC, Sharma RK, Patel SH, Shukla HR, Mittal AK, Kasiraj R, Misra AK, Prabhakar JH. 2003. Testicular development and its relationship to semen production in Murrah buffalo bulls. Theriogenology, 60:27-34.

Phillips C. 2002. Reproductive behavior. In: Cattle behaviour and welfare. Reproductive strategy. 2nd. Ed. Oxford: Blackwell Science Ltd, Cap.11, p.152-154.

Prabhu SS, Bhattacharya P. 1954. Influence of factors affecting sex drive on semen production of buffaloes. I - Physiological state of the "teaser" cow. Indian J Vet Sci Anim Husbandry, 24(1):35-50.

Prabhu SS. 1956. Influence of factors affecting sex drive on semen production - II. Indian J Vet Sci Anim Husbandry, 25(2):21-33.

Quezada-Casasola A, Martínez-Armendáriz KE, Carrera-Chávez JM, Pérez-Eguía E, RodríguezAlarcón CA, Avendaño-Reyes L. 2016. Effect of season on scrotal circumference, semen characteristics and testosterone serum concentration in Mexican 
Corriente and other beef breed bulls. Anim Reprod, 13:(4):787-794.

Quirino CR, Bergmann JA, Vale Filho VR, Andrade VJ, Pereira JC. 1999. Evaluation of four mathematical functions to describe scrotal circumference maturation in Nellore bulls. Theriogenology, 52:25-34

Saeed A, Chaudhry RA, Khan IH, Khan NU. 1990. Morphology of semen of buffalo bulls of different age groups. Physiol Reprod, 3:17-19.

Samo UM, Brohi NA, Kaka I, Qureshi TA, Memon MM. 2005. Study on sexual behaviour and seminal quality characteristics of Kundhi buffalo bulls. Pakistan J Bio Sci, 8(11):1628-1629.

Sansone G, Nastri MJF, Fabbrocini A. 2000. Storage of buffalo (Bubalis bubalus) semen. Anim Repr Sci, 62:55-76.

Silva AEDF, Unanian MM, Cordeiro CMT, De Freitas AR. 2002. Relação da Circunferência Escrotal e Parâmetros da Qualidade do Sêmen em Touros da Raça Nelore, PO [in portuguese]. Rev Bras Zootec, 31:115765.
Singh P, Sengupta BP, Tripathi VN. 2001. Effect of multiple showering and vitamin supplementation on sexual behavior, quality and freezability of buffalo bull semen. Asian-Aust. J Anim Sci, 14(2):184-188.

Vale WG. 1994. Collection, Processing and Deep freezing of buffalo semen. Buffalo $J, 2: 65-81$.

Vale WG. 1997. Sperm cryopreservation. Third Course on Biotechnology of Reproduction in Buffaloes. $J$ Buffalo Sci Tech, 4:129-140.

Vale WG, Ribeiro HFL, Sousa JS, Silva AOA, Barbosa EM, Rolim Filho S. 2008. Seleção e avaliação andrológica do reprodutor bubalino [in portuguese]. Rev Bras Reprod Anim, 32(2):141-155.

Vale WG. 2011. Avances biotecnológicos em reproducción de búfalos. Tecnología em Marcha, 24(5):89-90.

Zorzetto MF, Silva YFRS, S Zocca, Monteiro GA, Vexenat SC, I Martin, E Oba. 2016. Aspectos Físicos e Morfológicos do Sêmen de Bubalinos da Raça Murrah em Maturidade Sexual [in portuguese]. Veterinaria $e$ Zootecnia, 23(4):647-655. 